\title{
Cystoid Macular Oedema as a Presenting Feature of Vitreoretinal Lymphoma
}

\author{
Stephanie Chiu ${ }^{a}$ Hardeep Singh Mudhar ${ }^{b}$ Beth Harrison ${ }^{c}$ \\ Kurt Spiteri-Cornish $^{a} \quad$ Katharine Sears $^{\mathrm{a}}$ \\ a Department of Ophthalmology, Sheffield Teaching Hospitals NHS Foundation Trust, Sheffield, UK; \\ ${ }^{b}$ Department of Histopathology, National Specialist Ophthalmic Pathology Service (NSOPS), \\ Royal Hallamshire Hospital, Sheffield, UK; ${ }^{C}$ Department of Haematology, University Hospitals Coventry and \\ Warwickshire NHS Trust, Coventry, UK
}

\section{Established Facts}

- Vitreoretinal lymphoma (VRL) initially presenting with cystoid macular oedema (CMO) is rare.

- Causes of CMO in VRL include prior whole brain radiotherapy and chemotherapy as combined modality therapy, epiretinal membranes, and/or intraocular procedures.

\section{Novel Insights}

- We report on the case of a patient with VRL who presented with CMO. She had not previously undergone whole brain radiotherapy or any intraocular procedures.

- This case demonstrates that the presence of CMO does not definitively exclude the presence of VRL.

\section{Keywords}

Intraocular lymphoma · Macular oedema · Vitreoretinal lymphoma · Primary central nervous system lymphoma nal lymphoma (VRL), but the presence of the CMO made this unlikely. She underwent a diagnostic vitrectomy. Histology and immunohistochemistry showed the presence of a highgrade B-cell VRL.

(c) 2020 S. Karger AG, Basel

\begin{abstract}
A 69-year-old female presented with right vitreous cells and cystoid macular oedema (CMO). One year previously, she had received two cycles of attenuated methotrexate-based chemotherapy for primary central nervous system (CNS) lymphoma, abandoned due to toxicity. There was no past ocular history of note aside from mild cataract. Due to her history of previous CNS lymphoma, we suspected vitreoreti-
\end{abstract}

karger@karger.com

(C) 2020 S. Karger AG, Basel

www.karger.com/oop

Karger ${ }^{\prime}=$

\section{Introduction}

Vitreoretinal lymphoma (VRL), as opposed to orbital or adnexal lymphomas, is uncommon [1-4]. The exact incidence is unknown [5]. VRL is a high-grade nonHodgkin lymphoma (usually diffuse large B-cell lympho- 


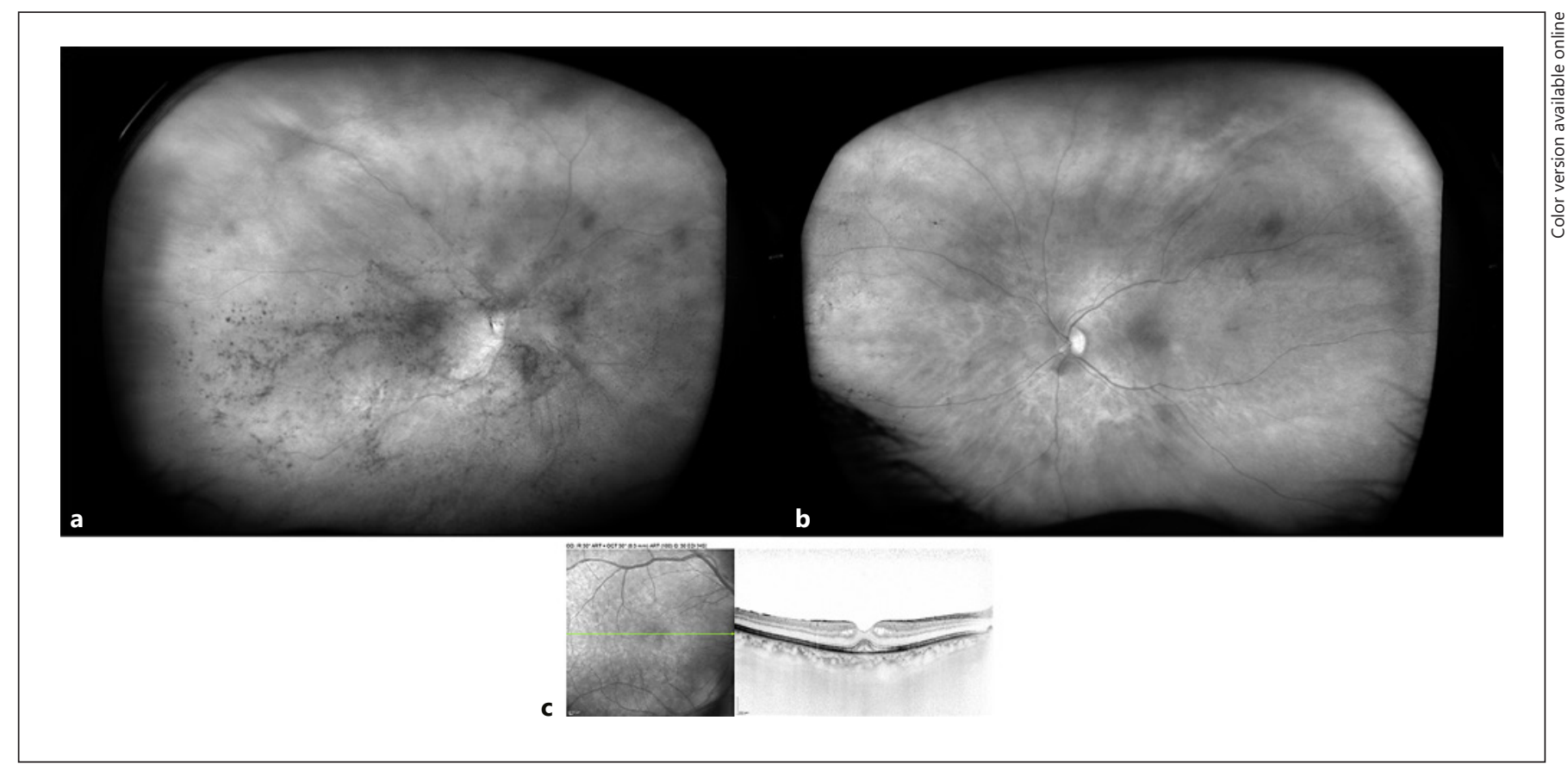

Fig. 1. a Optos ${ }^{\circledR}$ red free wide-field fundus imaging of the right symptomatic eye at presentation. Widespread vitreous cells are visible. $\mathbf{b}$ Optos ${ }^{\circledR}$ red free wide-field fundus imaging of the left asymptomatic eye at presentation. c Heidelberg Engineering $\mathrm{GmbH}$ ocular coherence tomography and infrared imaging of the right symptomatic eye at presentation showing cystoid macular oedema and subfoveal fluid.

ma) affecting the retina, vitreous, and/or optic nerve $[4$, $6,7]$. It is considered a subtype of primary central nervous system lymphoma (PCNSL), as opposed to systemic nonHodgkin lymphoma $[4,7]$. VRL can occur prior to, simultaneously, or after the onset of PCNSL. It is estimated that $35-90 \%$ of those who present initially with VRL will go on to develop CNSL, $15-25 \%$ who present initially with PCNSL will subsequently develop VRL, and $16-34 \%$ of cases of VRL present simultaneously with CNS involvement $[8,9]$.

Diagnosing VRL is notoriously difficult due to the fact that its usual presenting symptoms are often non-specific. Namely, VRL presents with blurred vision in $40-50 \%$ of patients, reduced visual acuity in $25-30 \%$, and floaters in $20-25 \%$ [10]. Chronic vitreous floaters are common in VRL, leading to it often been mistaken as a chronic posterior uveitis $[4,5]$. Creamy orange-yellow subretinal pigment epithelium lesions (solitary or multiple) may be found, and these may be associated with retinal detachment $[5,6]$. None of these are specific clinical signs pathognomonic of VRL. Moreover, many ophthalmologists elect to do a central vitreous core tap biopsy rather than sampling the entire vitreous. This is associated with an appreciable false negative rate because lymphoma cells tend to be concentrated mostly in the outer cortex rather than the core vitreous [11]. These factors all contribute to a delay in diagnosis.

Less commonly, VRL may be associated with iridocyclitis, optic neuropathy, vasculitis, and retinal haemorrhage [4-6]. Cystoid macular oedema (CMO) is rare in VRL [4-6].

\section{Case Report}

A 69-year-old female was referred to our tertiary ocular oncology department with a 2-week history of increased floaters and painless reduced central vision in her right eye. The referring ophthalmology department had started her already on preservativefree dexamethasone $1 \mathrm{mg} / 1 \mathrm{~mL}\left(\right.$ Dexafree $^{\circledR}$ ) and ketorolac $0.5 \%$ $\left(\right.$ Acular $\left.^{\circledR}\right)$ topical therapy.

One year prior to this, she had received dose-attenuated combination chemotherapy (rituximab, high-dose methotrexate, cytarabine) for the diagnosis of primary CNS lymphoma, with multifocal left sided white matter lesions. Chemotherapy was discontinued due to toxicities after two cycles. Radiotherapy was not given due to her age. When she presented with visual symptoms, her CNS lymphoma was thought to be in remission.

On presentation, her best-corrected visual acuities were 6/12 improving to $6 / 9$ with pinhole in her right eye, and 6/9 in the left. She had mild nuclear sclerotic cataracts in both eyes. There were 


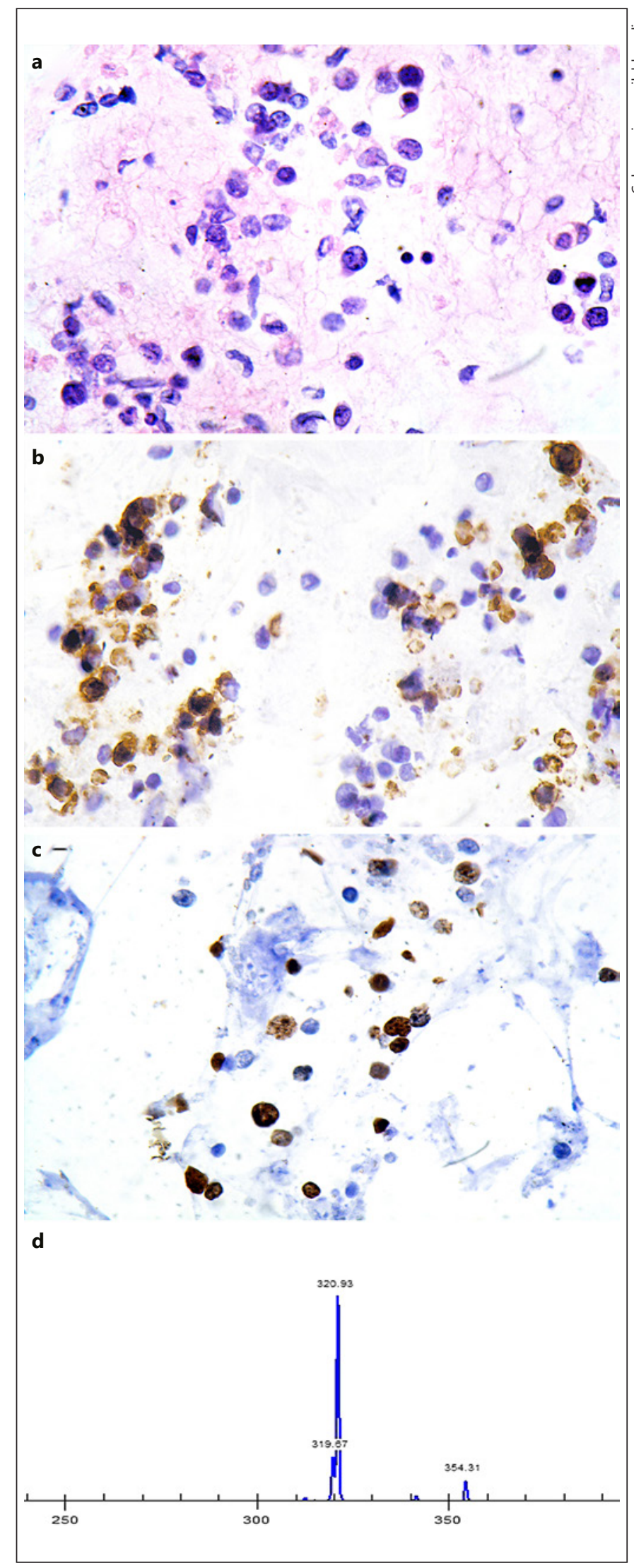

copious vitreous cells in the right eye with a small degree of $\mathrm{CMO}$ and subfoveal fluid (Fig. 1a, c). There were no signs of anterior uveitis, retinal vasculitis, subretinal deposits, or optic disc swelling. The left eye was normal (Fig. 1b).

Due to her history of PCNSL, VRL was suspected. However, on clinical grounds, the presence of the CMO made this unlikely. The differential diagnosis included paraneoplastic vitritis with CMO secondary to recurrent CNSL rather than progression of the disease into the eye. She proceeded to a pars plana diagnostic vitrectomy. Histology revealed highly atypical lymphoid cells (Fig. 2a) associated with eosinophilic lytic debris. This atypical lymphoid population was immunohistochemically positive for CD20, indicating a B-cell phenotype (Fig. 2b). Ki67 showed around 50-60\% of the $\mathrm{B}$ cells to be in the cycle (Fig. 2c). IgH B-cell monoclonality testing using BioRad 2 primers showed reproducible clones in all 3 reading frames (Fig. 2d). The cytological, immunohistochemical, and clonality findings were diagnostic of diffuse large B-cell lymphoma recurrence in the vitreous.

At her post-operative follow-up, she was found to have new vitreous cells in her left eye. External beam radiotherapy was delivered to both eyes. This provided a slight reduction in her intraretinal fluid (reduction in central macular thickness by $101 \mu \mathrm{m}$ ) and cleared the vitreous cells in both eyes. Unfortunately, 6 months after the radiotherapy, she experienced a relapse of both her cerebral and intraocular disease and died shortly afterwards.

\section{Discussion/Conclusion}

Cystoid macular oedema in VRL in those that have not been previously treated with radiation or intraocular surgery is uncommon. Cystoid macular oedema in VRL has been reported on previously, but these are found largely in patients who have previously received radiation or intraocular surgery. Cassoux et al. [12] reported in their series that 2 of 81 eyes with VRL had CMO, but 3 eyes in their series had undergone previous pars plana vitrectomy. Velez et al. [13] reported that 6 of 31 eyes with VRL were found to have CMO on fundus fluorescein angiography, but 5 of these eyes had previously undergone intraocular surgery. They did not specify for the 1 eye without previous intraocular surgery whether there had been previous radiation or other intraocular pathology such as an epiretinal membrane [13]. Turaka et al. [14] reported that 3 of 12 eyes with VRL had evi-

Fig. 2. a Haematoxylin and eosin-stained cytology preparation showing atypical lymphoid cells. b Immunohistochemistry staining with CD20 showing positive staining of the atypical lymphoid cells (brown is positive). c Ki67 immunohistochemistry staining the atypical lymphoid cell nuclei. d BioRad 2 IgH B-cell clonality testing showing a clonal peak, indicating a monoclonal B-cell population in the vitreous. 
dence of CMO on OCT, and 6 of 12 eyes had evidence of CMO on fundus fluorescein angiography, but all patients had undergone either chemotherapy, external beam radiotherapy, or a combination of both for existing systemic lymphoma. Jang et al. [15] found that 2 of 5 eyes with VRL had CMO, but 1 of these eyes had undergone previous pars plana vitrectomy, and the other had pre-existing CNS lymphoma, so one could presume that this patient had already undergone chemotherapy and/or radiotherapy. Recently, Carreras et al. [6] found that 6 of 15 eyes with VRL had presented with CMO, as detected on either fundus fluorescein angiogram or ocular coherence tomography. However, all of these had undergone either previous intraocular surgery or previous combined modality treatment with chemotherapy and whole brain radiotherapy prior to their presentation [6]. Subsequently, Deák et al. [16] published a case of VRL presenting with right CMO and multiple creamywhite subretinal lesions following right cataract surgery. This was treated with intravitreal dexamethasone implant (Ozurdex $\left.{ }^{\circledR}\right)$. Then, 6 months later his fellow eye developed CMO and was also treated with an Ozurdex implant. The patient was eventually diagnosed with VRL [16]. Despite this patient having CMO at the time of presentation, the right eye had previously been operated on, and cystoid macular oedema-like changes occurring in the unoperated fellow eye following cataract surgery have been described [17].

Our patient had undergone chemotherapy only, without whole brain radiotherapy. She also had not undergone any previous intraocular procedures. Therefore, we concluded that her CMO was a direct result of her VRL. This case demonstrates that CMO may occur in patients with VRL even when never previously treated with radiation or intraocular surgery.

\section{Statement of Ethics}

The subject has been fully anonymised. Written informed consent to publish this case and the images was provided by the patient's next of kin as the patient is now deceased.

\section{Conflict of Interest Statement}

The authors have no conflicts of interest to declare.

\section{Funding Sources}

The authors did not receive any funding from any sources for this case report.

\section{Author Contributions}

Stephanie J. Chiu, Ophthalmology Specialty Registrar - wrote the manuscript including Figure 1. Hardeep Singh Mudhar, Consultant Histopathologist - contributed to all of the histopathological data in the paper, contributed to Figure 2, manuscript revision, and final approval. Beth Harrison, Consultant Haematologist provided care regarding CNS lymphoma, manuscript revision, and final approval. Kurt Spiteri-Cornish, Consultant Ophthalmologist - provided care regarding the vitreoretinal biopsy, manuscript revision, and final approval. Katharine Sears, Specialty Doctor in Ophthalmology with special interest in Ocular Oncology and Uveitis - provided care regarding vitreoretinal lymphoma, manuscript revision, and final approval.

\section{References}

1 Mulay K, Narula R, Honavar SG. Primary vitreoretinal lymphoma. Indian J Ophthalmol. 2015 Mar;63(3):180-6.

2 Gill MK, Jampol LM. Variations in the presentation of primary intraocular lymphoma: case reports and a review. Surv Ophthalmol. 2001 May-Jun;45(6):463-71.

3 Coupland SE, Damato B. Understanding intraocular lymphomas. Clin Exp Ophthalmol. 2008 Aug;36(6):564-78.

4 Chan CC, Rubenstein JL, Coupland SE, Davis JL, Harbour JW, Johnston PB, et al. Primary vitreoretinal lymphoma: a report from an International Primary Central Nervous System Lymphoma Collaborative Group symposium. Oncologist. 2011;16(11):1589-99.
5 Sagoo MS, Mehta H, Swampillai AJ, Cohen VM, Amin SZ, Plowman PN, et al. Primary intraocular lymphoma. Surv Ophthalmol. 2014 Sep-Oct;59(5):503-16.

6 Carreras E, Salomão DR, Nadal J, Amin SR, Raja H, Grube TJ, et al. Macular edema is a rare finding in untreated vitreoretinal lymphoma: small case series and review of the literature. Int J Retina Vitreous. 2017 Apr;3(1): 15.

7 Saito T, Ohguro N, Iwahashi C, Hashida N. Optical coherence tomography manifestations of primary vitreoretinal lymphoma. Graefes Arch Clin Exp Ophthalmol. 2016 Dec;254(12):2319-26.
8 Grimm SA, McCannel CA, Omuro AM, Ferreri AJ, Blay JY, Neuwelt EA, et al. Primary CNS lymphoma with intraocular involvement: International PCNSL Collaborative Group Report. Neurology. 2008 Oct;71(17): 1355-60.

9 Grimm SA, Pulido JS, Jahnke K, Schiff D, Hall AJ, Shenkier TN, et al. Primary intraocular lymphoma: an International Primary Central Nervous System Lymphoma Collaborative Group Report. Ann Oncol. 2007 Nov; 18(11): 1851-5.

10 Fend F, Ferreri AJ, Coupland SE. How we diagnose and treat vitreoretinal lymphoma. Br J Haematol. 2016 Jun;173(5):680-92. 
11 Mudhar HS, Sheard R. Diagnostic cellular yield is superior with full pars plana vitrectomy compared with core vitreous biopsy. Eye (Lond). 2013 Jan;27(1):50-5.

12 Cassoux N, Merle-Beral H, Leblond V, Bodaghi B, Miléa D, Gerber S, et al. Ocular and central nervous system lymphoma: clinical features and diagnosis. Ocul Immunol Inflamm. 2000 Dec;8(4):243-50.

13 Velez G, Chan CC, Csaky KG. Fluorescein angiographic findings in primary intraocular lymphoma. Retina. 2002 Feb;22(1):37-43.
14 Turaka K, Bryan JS, De Souza S, Gordon AJ, Kwong HM Jr, Ziemianski MC, et al. Vitreoretinal lymphoma: changing trends in diagnosis and local treatment modalities at a single institution. Clin Lymphoma Myeloma Leuk. 2012 Dec;12(6):412-7.

15 Jang HS, Sepah YJ, Sophie R, Bittencourt MG, Ferraz D, Hanout M, et al. Longitudinal spectral domain optical coherence tomography changes in eyes with intraocular lymphoma. J Ophthalmic Inflamm Infect. 2013 Sep;3(1): 59.
16 Deák GG, Sneed SR, Jampol LM. Cystoid macular edema in the setting of primary vitreoretinal lymphoma. Retin Cases Brief Rep. 2018 Jul. Published ahead of print. https://doi. org/10.1097/ICB.0000000000000797.

17 Sigler EJ. Managing Pseudophakic Cystoid Macular Edema. Retinal Physician. 2015 Nov-Dec. Available from: https://www.retinalphysician.com/issues/2015/nov-dec/managing-pseudophakic-cystoid-macular-edema. 